\title{
Parameterization of high magnetic field gradient fractionation columns for applications with Plasmodium falciparum infected human erythrocytes
}

\author{
Stephan Karl11,2, Timothy ME Davis ${ }^{2}$ and Tim G St Pierre*1
}

\begin{abstract}
Background: Magnetic fractionation of erythrocytes infected with Plasmodium falicparum has several research uses including enrichment of infected cells from parasite cultures or enhanced detection of $P$. falciparum gametocytes. The aim of the present study was to quantitatively characterize the magnetic fractionation process and thus enable optimization of protocols developed for specific uses.

Methods: Synchronized cultures of $P$. falciparum parasites incubated with human erythrocytes were magnetically fractionated with commercially available columns. The timing of the fractionation experiments was such that the parasites were in second half of their erythrocytic life cycle with parasite densities ranging from 1 to 9\%. Fractionations were carried out in a single pass through the columns. Cells were enumerated and differentiated in the initial samples as well as in the positive and negative fractions. The capture of cells by the fractionation column was described by a saturation binding model.
\end{abstract}

Results: The magnetic binding affinity to the column matrix was approximately 350 times greater for infected cells compared with uninfected cells. The purity of infected cells in the captured fraction was generally $>80 \%$ but decreased rapidly (to less than $50 \%$ ) when the number of infected cells that passed through the column was substantially decreased (to less than $9 \pm 5 \times 10^{5}$ cells). The distribution of captured parasite developmental stages shifted to mature stages as the number of infected cells in the initial samples and flow rate increased. The relationship between the yield of infected cells in the captured fraction and flow rate of cells conformed to a complementary cumulative log-normal equation with flow rates $>1.6 \times 10^{5}$ cells per second resulting in yields $<50 \%$.

Conclusions: A detailed quantitative analysis of a batchwise magnetic fractionation process for malaria infected erythrocytes using high gradient magnetic fractionation columns was performed. The models applied in this study allow the prediction of capture efficiency if the initial infected cell concentration and the flow rate are known.

\section{Background}

Plasmodium species have complex life cycles involving the invertebrate mosquito and human host [1]. In humans, the parasite undergoes asexual multiplication in red blood cells where haemoglobin provides the main source of the protein necessary for its development. Haemoglobin is transported in aliquots to the parasitic lyso-

\footnotetext{
* Correspondence: stpierre@physics.uwa.edu.au

1 School of Physics, M013, The University of Western Australia, 35 Stirling Highway, Crawley WA 6009, Australia

Full list of author information is available at the end of the article
}

some and digested [2]. Haem groups are by-products of this process. The iron in the haem rapidly oxidizes and haem monomers are converted into an inert crystalline and paramagnetic material named haemozoin or malaria pigment which accumulates in infected erythrocytes $[3,4]$. The rate of haemozoin formation correlates with parasite metabolic activity and peaks at the trophozoite stage of development [5].

Magnetic fields can be used to separate Plasmodiuminfected blood samples into positive and negative fractions with a higher and lower percentage of infected cells, 
respectively, than the initial sample [6,7]. The most commonly used magnetic cell fractionation system, including that for malaria parasites, is the MACS system manufactured by Miltenyi Biotec (Bergisch-Gladbach, Germany). The MACS system utilizes columns containing a matrix of magnetic beads as magnetic field gradient enhancing medium. When placed into an external magnetic field, the beads become magnetized. Strong local magnetic fields and field gradients facilitate binding of cells with magnetic susceptibilities sufficiently different from their surrounding medium. These cells can be eluted from the columns when the external magnetic field is removed.

Apart from its usage for parasite synchronization $[8,9]$ and in-vitro biochemical [10], biophysical [11], molecular $[9,12]$ and immunological studies $[13,14]$, magnetic fractionation has found its application in the isolation of rare parasitized cells from peripheral blood of malaria infected patients $[13,15,16]$.

In general, there are two classes of Plasmodium falciparum infected cells, to which magnetic fractionation is applicable and which may occur in very low concentrations in peripheral blood. Firstly, asexual mature stages of $P$. falciparum, which express proteins that facilitate cytoadherence to the vascular endothelium [17,18]. Apart from in severe malaria infections, these stages are very rarely observed on blood smears because the vast majority is sequestered. Magnetic fractionation has been used to isolate these mature asexual stages $[15,16]$.

Secondly, magnetic fractionation can be used to improve detection and quantification of gametocytes from peripheral blood $[15,16,19,20]$. Gametocytes, the sexual stages of Plasmodium that are taken up by the mosquito host, also contain haemozoin crystals but do not cytoadhere in their final stages of development. They are typically much less numerous than asexual parasite stages and their prevalence is often underestimated $[21,22]$.

Magnetic fractionation can be applied to the other Plasmodium species that infect humans [16,20]. Plasmodium vivax, Plasmodium malariae and Plasmodium ovale do not cytoadhere, and late trophozoite and schizont stages of these species are found more frequently in peripheral blood $[23,24]$. However, laboratory studies are usually confined to $P$. falciparum since continuous culture of the other species is not currently feasible.

Although different customized magnetic fractionators have been applied, most studies have used the commercially available MACS system.

There has been no quantitative analysis of the magnetic fractionation process applied to malaria infected cell suspensions. Such data are required to establish conditions for optimal purity and yield such as when infected cell densities are too low to be detected by conventional light microscopy. In the present study this analysis was per- formed using cultured P. falciparum and the widely-available MACS equipment.

\section{Methods}

\section{Continuous parasite culture}

The laboratory-adapted Plasmodium falciparum strains 3D7 and W2mef were cultured in RPMI 1640 HEPES (Sigma Aldrich, St Louis, MO) supplemented with 92.6 mg/L L-glutamine (Sigma Aldrich, St Louis, MO), 500 $\mathrm{mg} / \mathrm{L}$ gentamicin (Sigma Aldrich, St Louis, MO), $50 \mathrm{mg} / \mathrm{L}$ hypoxanthine (Sigma Aldrich, St Louis, MO) and 10\% v/v pooled human plasma. Cultures were maintained with daily changes of culture medium at 5\% haematocrit and diluted with red blood cells when parasitaemia exceeded $5 \%$. Cultures were incubated in an airtight desiccator cabinet at $37^{\circ} \mathrm{C}$ in an atmosphere containing between $5 \%$ to $10 \%$ oxygen. The low oxygen atmosphere was generated by gassing the cabinet with a mixture of $1 \% \mathrm{O}_{2}$ and $5 \%$ $\mathrm{CO}_{2}$ balanced in $\mathrm{N}_{2}$ (BOC gases, Perth, Australia) at 1.01.5 bar for 60-90 seconds each time it had been opened.

\section{Synchronization}

The accumulation of haemozoin is a gradual process over the $48 \mathrm{~h}$ of the intraerythrocytic life cycle of Plasmodium falciparum. The conversion rate is maximal at the trophozoite stage, as are many of the parasite's metabolic processes. The assays described below required parasites at the same stage of development after merozoite invasion. This synchronization was achieved by suspension of the cells in 5\% w/v sorbitol (Sigma Aldrich, St Louis, MO) for $12 \mathrm{~min}$ to allow destruction of mature parasite stages through osmotic pressure change, followed by re-suspension of erythrocytes containing viable parasite forms in culture medium. Such single-step sorbitol synchronization produces cultures that contain parasites, which are ring and early trophozoite stages that have developed for an estimated maximum time of $18 \mathrm{~h}$ after merozoite invasion.

\section{Magnetic fractionation}

The present study comprised a total of 45 magnetic fractionation experiments. Of these, 30 were conducted with varying initial cell concentrations (15 experiments with the chloroquine and mefloquine sensitive strain 3D7, and 15 with chloroquine and mefloquine resistant strain W2mef) and 15 experiments with varying flow rates (10 with 3D7 and 5 with W2mef).

Magnetic fractionations were conducted $24 \mathrm{~h}$ after synchronization, so that parasites were in the second half of the life cycle (24 h-42 h). A MidiMACS magnet, a MACSmultistand and LS columns (Miltenyi Biotech, Bergisch Gladbach, Germany) were used for the experiments. The columns were placed into the magnet unit (which generates a magnetic field of approximately $0.65 \mathrm{~T}$ ) and primed 
with $0.7 \mathrm{~mL}$ sterile filtered magnetic fractionation buffer (MFB, PBS pH 7.4, containing $0.5 \mathrm{~g} / \mathrm{L}$ bovine serum albumin and $0.0037 \mathrm{~g} / \mathrm{L}$ EDTA) equilibrated to room temperature. Before passage over the column, each sample of erythrocytes was washed once in PBS, spun down, and then resuspended in $5 \mathrm{~mL}$ MFB in $15-\mathrm{mL}$ centrifuge tubes (BD Biosciences, San Jose, CA) and incubated at room temperature for at least $10 \mathrm{~min}$.

Different flow rates were achieved by attachment of sterile syringe needles (BD Biosciences, San Jose, CA) with different internal diameters and lengths to the end of the MACS columns. The volumetric flow rate was determined by measuring the time it took for a sample of defined volume to pass through the column. The effluent (hereafter termed the negative fraction) was collected in $50 \mathrm{~mL}$ cone tubes (BD Biosciences, San Jose, CA).

The columns were then washed with $2 \times 1 \mathrm{~mL}$ MFB and removed from the magnet. The sterile needle was disconnected and the cells captured in the column (hereafter termed the positive fraction) were eluted into $15-\mathrm{mL}$ centrifuge tubes (BD Biosciences, San Jose, CA) by washing with $1 \times 5 \mathrm{~mL} \mathrm{MFB}$.

\section{Measurements of cell concentrations}

All $15 \mathrm{~mL}$ and $50 \mathrm{~mL}$ cone tubes were weighed before and after each experiment to determine the volumes of the cell suspension in the initial samples, and the positive and negative fractions. The density of the fractionation buffer was determined by weighing a $1 \mathrm{~mL}$ volume measured using a calibrated pipette on a precision laboratory scale multiple times $(n=6)$. The density of the magnetic fractionation buffer was $0.994 \pm 0.02 \mathrm{~g} / \mathrm{mL}$.

A volume of $200 \mu \mathrm{L}$ of cell suspension was removed from both the initial sample and the negative fraction and measured with a cell counter (Cell Dyn 4000, Abbott, Lane Cove, NSW, Australia) which reliably measures erythrocyte concentrations above a threshold of $2 \times 10^{3}$ cells per $\mathrm{mL}$. The initial and negative fractions contained an average of $1.16 \times 10^{8}$ cells per mL (range: $4.97 \times 10^{5}$ cells $/ \mathrm{mL}$ to $7.62 \times 10^{8}$ cells $/ \mathrm{mL}$ ), which is well above the required threshold of the instrument.

Because the cell concentrations in the positive fractions can be much smaller, a haemocytometer (Neubauer type, Brand GmbH + Co KG, Wertheim, Germany) was used to determine the cell concentrations in the positive fractions. An aliquot of $10 \mu \mathrm{L}$ cell suspension was introduced into the counting chamber of the haemocytometer and the red blood cell concentration determined by counting the number of red blood cells in 4 large squares $\left(0.4 \mathrm{~mm}^{3}\right)$ of the counting chamber.

\section{Flow cytometry}

Since only parasitized erythrocytes contain DNA, fluorescence staining of the DNA and subsequent flow cytometry can be used to reliably discriminate between infected and uninfected erythrocytes and to determine total parasitaemia [25-27]. Aliquots of $1 \mu \mathrm{L}$ of packed cells from the initial and the negative fractions, and from $1 \mathrm{~mL}$ of the positive fractions, were suspended in $1 \mathrm{~mL}$ PBS (pH 7.4) and the double-stranded DNA was stained by addition of $1 \mu \mathrm{L}$ Sybr Green nucleic acid gel stain $(10,000 \times$ concentrate in DMSO, Invitrogen Molecular Probes, Mulgrave, Australia). The samples were incubated in the dark at $37^{\circ} \mathrm{C}$ for $15 \mathrm{~min}$. Excess stain was removed by washing once in PBS ( $\mathrm{pH}$ 7.4). The samples were then fixed in a PBS ( $\mathrm{pH}$ 7.4) solution containing $2.5 \% \mathrm{v} / \mathrm{v}$ glutaraldeyde and $1 \% \mathrm{v} / \mathrm{v}$ paraformaldehyde for 60 minutes at $4^{\circ} \mathrm{C}$. The fixative solution was replaced by PBS (pH 7.4) and the samples were stored at $4^{\circ} \mathrm{C}$ in the dark until analysis on a FACSCanto II flow cytometer (BD Biosciences, San Jose, CA). The flow cell in this instrument was a quartz cuvette and the light source a 20 $\mathrm{mW} / 488 \mathrm{~nm}$ solid state argon laser. At the flow cell, the effective power of this light source is typically $15 \mathrm{~mW}$. The laser beam had an elliptical geometry with $9 \mathrm{~mm}$ and $65 \mathrm{~mm}$ being the short and long axes of the beam profile respectively. The instrument was equipped with photomultiplier tube detectors to detect wavelengths emitted from interaction with the $488 \mathrm{~nm}$ argon laser in the ranges of $750-810 \mathrm{~nm}, 670-735 \mathrm{~nm}, 610-637 \mathrm{~nm}$ and 564$606 \mathrm{~nm}$. Sybr Green has its emission maximum at $520 \mathrm{~nm}$ and therefore the 564-606 nm channel was selected from those available on the instrument for detection. Fifty thousand events were acquired from each sample.

\section{Differential parasite count}

Thin blood smears were prepared from each initial sample and from the positive and negative fractions in each experiment. Parasite development was divided into 6 stages: Rings (R), early trophozoites (ET), late trophozoites (LT), schizonts (S), segmenters (SEG) and gametocytes $(\mathrm{G})$. Photomicrographs depicting parasites in the different developmental stages are shown in Figure 1. One hundred parasites were counted and staged on each blood smear.

\section{Results}

The distributions of parasite stages in the initial samples as well as in the positive and negative fractions are shown in Figure 2.

The late trophozoite stage was the most prevalent stage in all fractions. Few early trophozoites and rings were seen in the positive fractions whereas schizonts, segmenters and gametocytes were infrequent in the negative fractions. Rings and gametocytes together accounted for $<1 \%$ of the total parasite population in each of the fractions. The average total recovery of infected cells in the positive fractions in all 45 experiments was $88 \%$ (95\% 


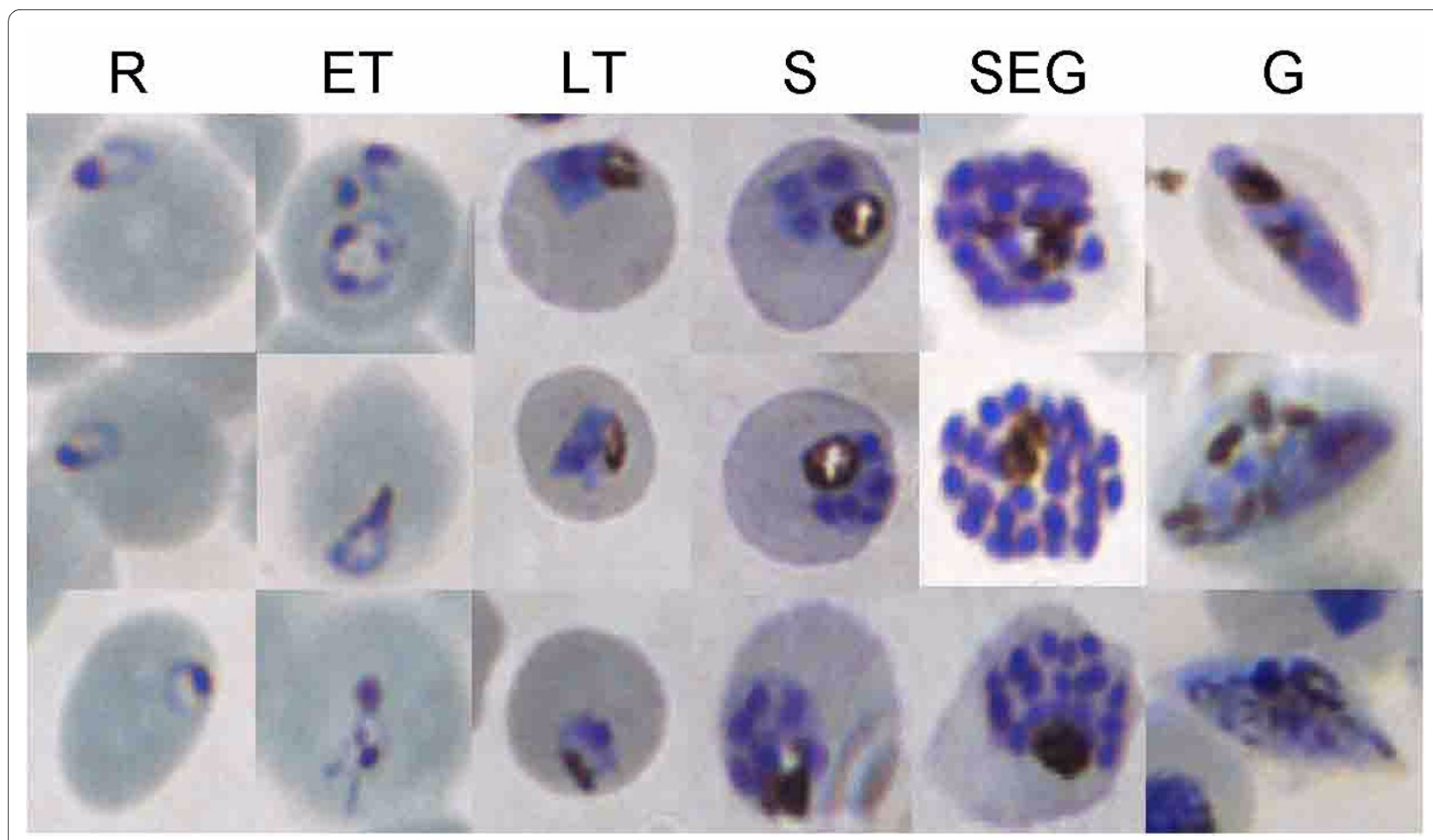

Figure 1 Exemplary images of infected erythrocytes at different stages of infection. Three examples of each of the different intraerythrocytic developmental stages of Plasmodium falciparum reflecting the classification used in the present study. An early trophozoite (ET) was distinguished from a ring stage (R) when the cytoplasm of the parasite had begun to expand but no haemozoin crystals were visible. A late trophozoite (LT) contained haemozoin and not more than one nucleus. A schizont (S) contained up to 8 nuclei. Parasites with $>8$ nuclei were classified as segmenters (SEG). Examples of gametocytes (G) are also shown. Images were obtained on a Nikon Eclipse TE2000 -N Microscope with a 1000x optical magnification with a Nikon LH-M100CB-1 Camera.

confidence interval: $81 \%-95 \%)$. The parasitaemia in the intial samples ranged from $0.92 \%$ to $8.71 \%$, from $56.4 \%$ to $96.7 \%$ in the positive fractions and from $0.51 \%$ to $3.34 \%$ in the negative fractions.

Figure 3 shows the numbers of infected and uninfected cells that bound to the column against the number in the initial sample.

A simple saturation binding model (Equation 1 below) which estimates the number of available binding sites in the column and compares the relative affinities of infected and uninfected cells for the bead matrix was fitted independently to the two sets of data:

$$
N_{P}=\frac{B_{\max }}{1+10^{\left(\log K_{D}-\log N_{I}\right)}},
$$

where $B_{\max }$ is the effective number of available binding sites in the column, $N_{I}$ is the number of cells in the initial fraction and $N_{P}$ is the number of cells in the positive fraction. The model takes no account of competition between the infected and uninfected cells for binding sites. This simplification can be justified on the basis that, in all experimental situations, the number of uninfected cells that bind to the column will always be much lower than the number of available binding sites.

When applied to the infected cells, the model yielded an estimate of the number of potential binding sites in the column of $1.27( \pm 0.27) \times 10^{8}$. This number approximates the number of cells in $13 \mu \mathrm{L}$ of packed red blood cells (at $10^{7}$ cells per $\mu \mathrm{L}$ packed cells). The half saturation constant $K_{D}$ for infected cells was $2.18( \pm 0.95) \times 10^{8}$. The predicted maximum number of uninfected cells was very similar to the number of infected cells $\left(1.29 \times 10^{8}\right)$. However the curve fit for the uninfected cells was suboptimal since the applied uninfected cell densities are all much lower than the predicted $K_{D}$ for uninfected cells of $7.7 \times$ $10^{10}$. It should be noted that the $K_{D}$ for uninfected cells corresponds to $7.7 \mathrm{~mL}$ packed red blood cells and that application of cell volumes of this magnitude to the columns is not feasible. Based on the ratio of the $K_{D}$ values it can be estimated that the column binding affinity of infected cells (with the distribution of parasite developmental stages described earlier) is about 350 times higher than that for uninfected cells. 


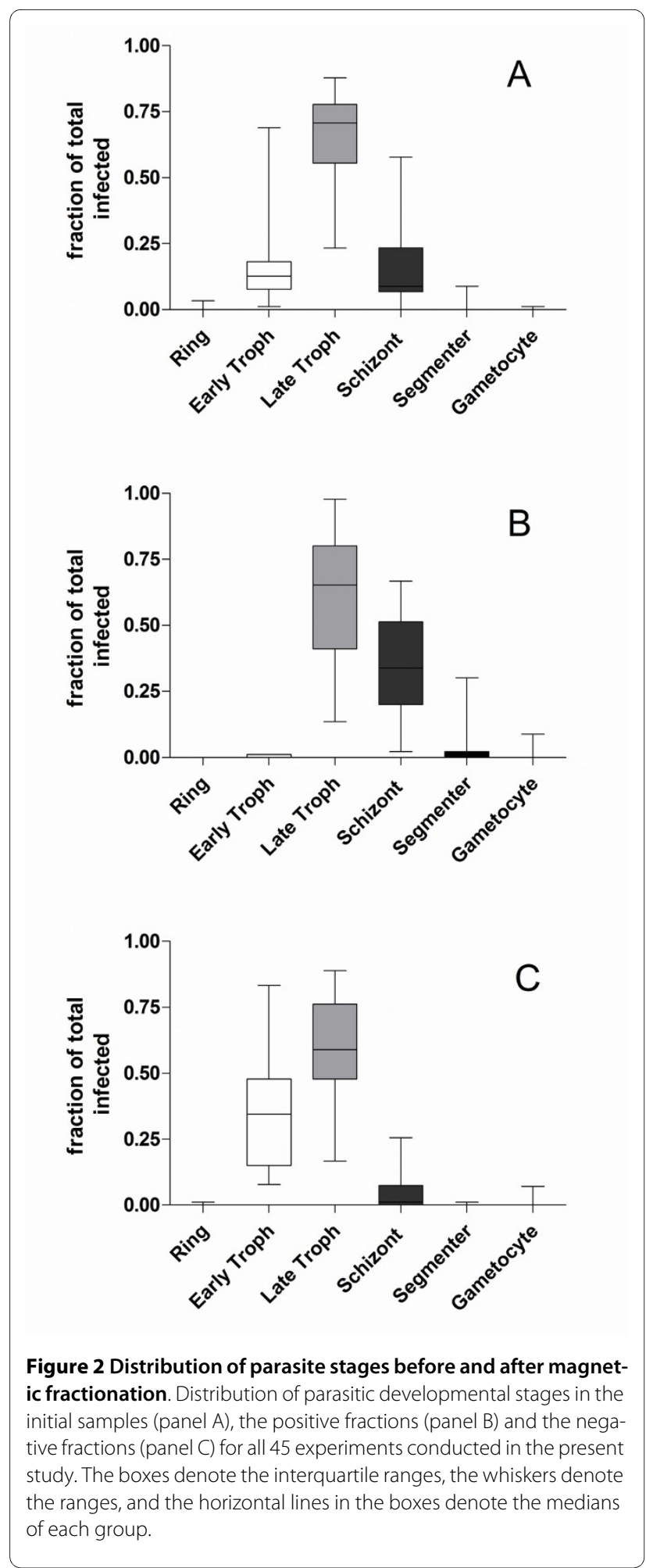

Despite the initial assumptions inherent in the model, there was evidence for competition for binding between infected and uninfected cells at very low infected cell densities. Since the binding affinity of the uninfected cells is low, a standard competition binding analysis could not

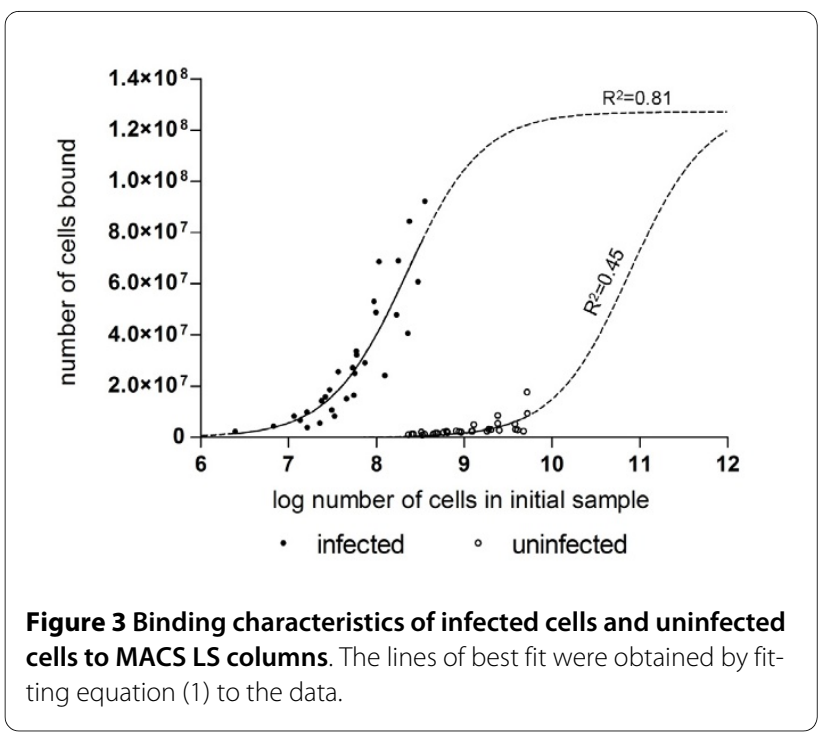

be conducted. However, Figure 4 shows a decrease in the purity of the infected cells in the positive fraction as the number of infected cells in the initial sample is substantially decreased, indicating competition for binding sites. The data in Figure 4 were fitted to a cumulative log normal distribution of the form:

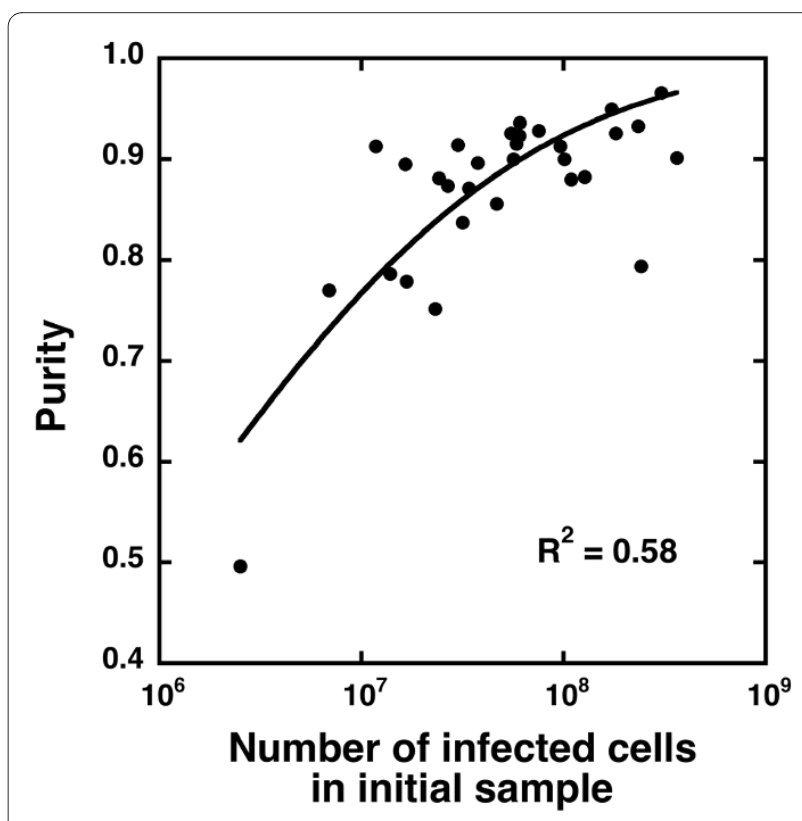

Figure 4 Purity of infected cells in the positive fraction against number of infected cells in the initial sample. The solid line is a fit of equation (2) to the data. 


$$
\text { Purity }=\frac{1}{2} \operatorname{erfc}\left[-\frac{\ln n_{i}-\ln n_{50 \%}}{\sqrt{2} \sigma_{\text {purity }}}\right] \text {, }
$$

where $n_{i}$ is the number of infected cells in the initial sample and $n_{50 \%}$ and $\sigma_{\text {purity }}$ are fitted parameters and the complementary error function is given by

$$
\operatorname{erfc}(x)=\frac{2}{\sqrt{\pi}} \int_{x}^{\infty} e^{-t^{2}} d t .
$$

The parameter $n_{50 \%}$ was found to be $9( \pm 5) \times 10^{5}$ and is the number of infected cells in the initial sample below which the equation predicts that the purity in the positive fraction will be less than $50 \%$. The parameter $\sigma_{\text {purity }}$ was $3.3 \pm 0.5$.

With increasing numbers of infected cells in the initial sample, there was a significant increase in the proportion of haemozoin-containing infected cells (late trophozoites, schizonts, segmenters and gametocytes) in the negative fractions (Spearman correlation coefficient 0.37, $\mathrm{p}=0.04$, $\mathrm{n}=30$ ). This positive association is most likely related to column saturation since at the higher initial numbers of infected cells the capacity of the columns is exceeded by approximately 3 -fold resulting in approximately $75 \%$ of the binding sites being occupied (see Figure 3). Hence, there is a higher probability of haemozoin-containing cells passing through the column without binding at these higher initial infected cell numbers. Furthermore, the proportion of infected cells in the positive fraction in the form of schizonts, segmenters and gametocytes increased with higher initial cell concentrations (Figure 5A). A similar but more marked increase in the proportion of infected cells in the positive fraction in the form of schizonts and segmenters was found with increasing flow rate (Figure $5 \mathrm{~B}$ ). Both phenomena can be explained by the stronger magnetic force exerted on schizonts and segmenters. These stages contain higher quantities of haemozoin and thus bind preferentially to the bead matrix.

The flow rate had a strong influence on the number of infected cells retained in the fractionation columns. With increasing flow rate, the infected cell yield in the positive fraction decreased monotonically (Figure 6A). A complementary cumulative log-normal function,

$$
\text { Yield }=\frac{1}{2} \operatorname{erfc}\left\lfloor\frac{\ln F-\mu_{1}}{\sqrt{2} \sigma_{1}}\right\rfloor,
$$

was fitted to the data where $\mathrm{F}$ is the flow rate through the column. The fit yielded the following parameters with a coefficient of determination $\mathrm{R}^{2}=0.65: \mu_{1}=-5.7 \pm 0.2$ and $\sigma_{1}=1.3 \pm 0.3$. A flow rate of $e^{\mu 1}(=0.0034) \mathrm{mL} / \mathrm{s}$ corresponds to that at which the equation predicts the yield to be $50 \%$. The product of flow rate and concentration of infected cells in the initial sample $\left(F \times c_{i}\right)$ correlated more strongly with the infected cell yield than flow rate alone (Figure 6B). When the following equation was fitted to the data in Figure 6B,

$$
\text { Yield }=\frac{1}{2} \operatorname{erfc}\left\lfloor\frac{\ln \left(F c_{i}\right)-\mu_{2}}{\sqrt{2} \sigma_{2}}\right\rfloor
$$

an improved coefficient of determination $\left(\mathrm{R}^{2}=0.87\right)$ was obtained together with values of $\mu_{2}$ and $\sigma_{2}$ of $12.0 \pm$ 0.1 and $1.03 \pm 0.15$ respectively. The fitted equation predicts an infected cell yield of $50 \%$ when the product of flow rate and concentration of infected cells in the initial sample is $e^{\mu 2}\left(=1.6 \times 10^{5} \mathrm{cells} / \mathrm{s}\right)$.

There was no relationship between the purity of the positive fractions and flow rate. The average purity in the positive fractions in the flow rate experiments $(\mathrm{n}=15)$ was $83.5 \pm 10.5 \%$.

There were no statistically significant differences in any of the derived parameters between the two different strains of $P$. falciparum used in the present study.

\section{Discussion}

Many studies have applied magnetic fractionation in malaria research but only few have made any attempt to quantify the fractionation results. A common theme in all previous studies of the actual magnetic fractionation process $[8,15,16,19,20]$ is the generation of qualitative information on 'enrichment' (fold increase), 'concentration' or 'purification' based on blood smear microscopy. However, assessing purity in the positive fractions based on slide counts alone can be misleading and does not provide information on capture efficiency and the distribution of parasitized cells recovered in the different fractions. The present study shows clearly that purity can be influenced by a number of different factors related to the nature of the parasite, the blood sample and its infected red cell density. In addition, some $P$. falciparum strains may bind to uninfected cells to form rosettes $[28,29]$, a process that could theoretically lead to major losses in purity despite the use of anticoagulants and possible mechanical disruption of rosettes during sample processing. Furthermore, purity in the positive fraction is dependent on the volume of buffer applied to elute unbound cells. While larger buffer volumes might increase the purity, this strategy will decrease the numbers of infected cells recovered in the positive fraction, since the infected cells are not tightly bound to the column matrix and will be eluted with uninfected cells. 


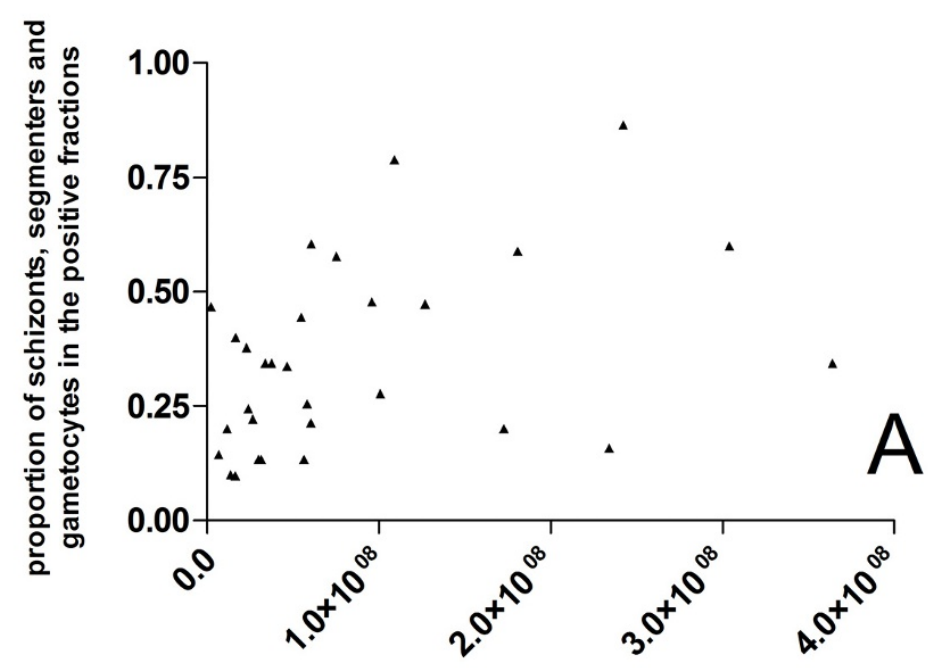

infected cell number in initial sample

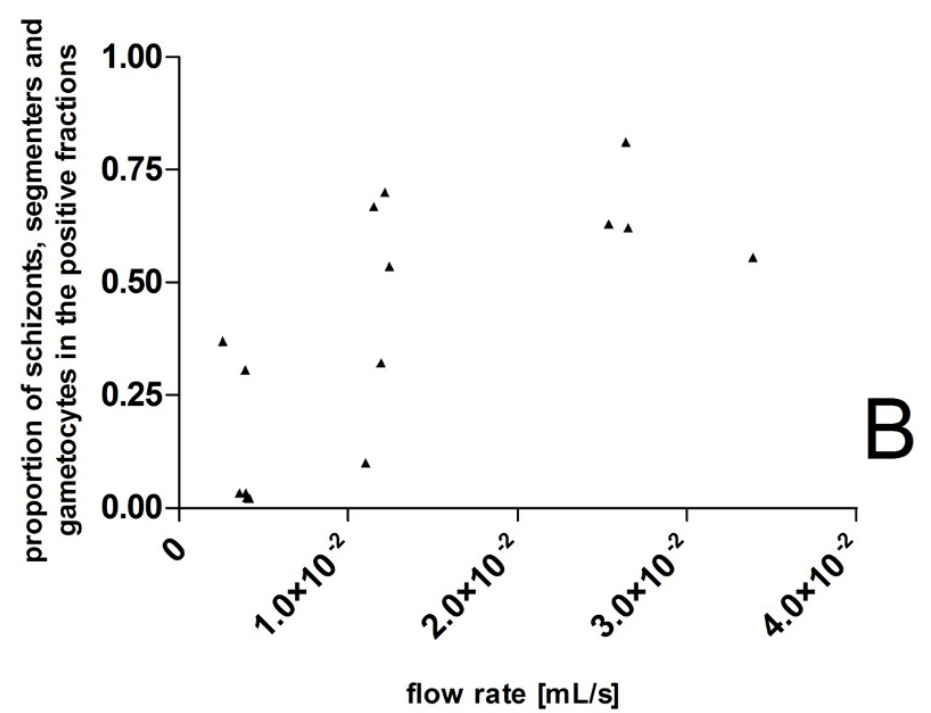

Figure 5 Influence of flow rate and initial cell number on the stage distribution in the positive fractions. Shift in the proportion of infected cells in the positive fractions that are schizonts, segmenters or gametocytes with changing initial infected cell number (panel A, Spearman correlation coefficient: $+0.48, p=0.0068, n=30$ ) and flow rate (panel $B$, Spearman correlation coefficient: $+0.67, p=0.0064, n=15$ ). Stages containing higher quantities of haemozoin bind preferentially to the bead matrix at higher initial infected cell numbers and higher flow rates.

Iron in methaemoglobin exhibits paramagnetic characteristics similar to those of haemozoin iron. In healthy erythrocytes, the amount of methaemoglobin is usually $<1 \%$ of the total haemoglobin but it may exceed $8-10 \%$ in methaemoglobinaemia [30]. Malaria induced methemoglobinemia has been reported but is related to free methemoglobin generated due to the increased rupture of healthy erythrocytes during malaria infection [31,32]. Only intra-erythrocytic elevation of methemoglobin lev- els could lead to a significant retention of uninfected cells in magnetic fractionation columns. The present study shows that the binding kinetics strongly favour infected cells which have an affinity that is two orders of magnitude higher than that of uninfected cells.

There were no parasite strain-specific differences in found in the present data. However, it should be noted that different parasite strains may vary slightly in their growth characteristics over a single life cycle. This could 

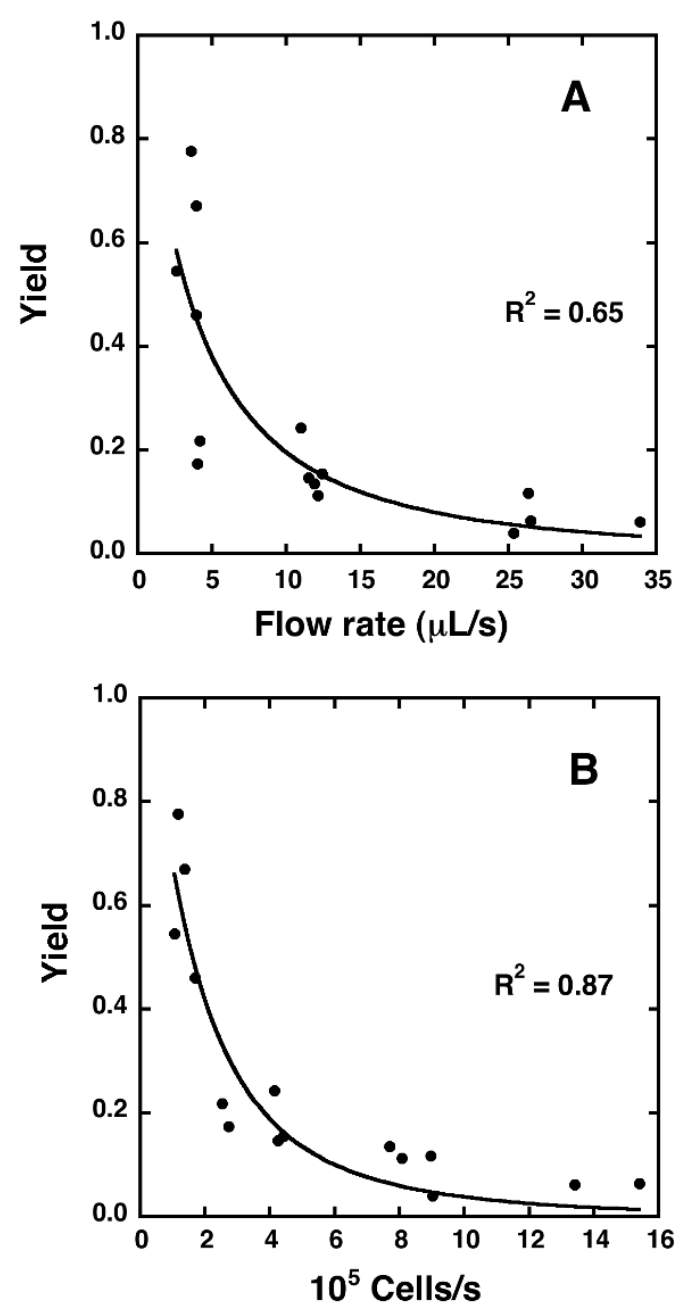

Figure 6 Dependence on the infected cell yield in the positive fractions on flow rate and initial cell concentration. Dependence of the yield of infected cells in the positive fraction (A) on flow rate through the column and (B) on the product of flow rate and concentration of infected cells in the initial sample. The solid lines are fits of equations (3) and (4) to the data.

theoretically lead to small differences in the amount of haemozoin present in infected cells $24 \mathrm{~h}$ after synchronization [33], the time point at which the present experiments were conducted.

While flow rate did not influence purity, there was a monotonic decrease in infected cell yield for all stages of infection as flow rate increased. This suggests that haemozoin containing cells are not strongly retained in the MACS columns. The magnetic fractionation process may be more comparable with column chromatography, where the retention time of infected cells in the columns is a function of haemozoin content. The present study shows that the highest capture efficiencies in the magnetic fractionation columns are achieved at a minimal flow rate and minimal concentration of infected cells. The highest capture efficiencies achieved in this study were $>75 \%$ infected cells. While the number of uninfected cells in the initial sample did have an effect on infected cell purity in the positive fractions, it did not influence capture efficiency significantly. Therefore, in a clinical setting where only a few haemozoin containing cells circulate in peripheral blood, the probability of capturing infected cells can be increased by lowering the flow rate and increasing the sample volume without diminishing capture efficiency. The models applied in this study allow the prediction of capture efficiency if the initial infected cell concentration and the flow rate are known.

\section{Conclusion}

The present study is the most detailed quantitative characterization of magnetic fractionation of erythrocytes infected with Plasmodium falciparum conducted to date. Although the present analysis was confined to the use of one kind of separation column and specific parasite strains, the present approach can be used to guide quantitation of any batch-wise magnetic cell fractionation process used in malaria-infected erythrocytes. If magnetic fractionation is used for concentration of microscopically undetectable numbers of haemozoin-containing infected cells (e.g. from patient blood), the protocol presented here provides the means to estimate the density of these cells in the initial sample from a blood smear prepared from the positive fraction.

\section{List of Abbreviations}

95\% CI: 95\% confidence interval; DMSO: dimethyl sulfoxide; DNA: desoxyribonucleic acid; EDTA: ethylenediaminetetraacetic acid; ET: Early trophozoite; G: gametocyte; HEPES: 4-(2-hydroxyethyl)-1-piperazineethanesulfonic acid; LT: late trophozoite; MACS: magnetically activated cell sorting; MFB: magnetic fractionation buffer; PBS: phosphate buffered saline; R: ring stage; RPMI: Ross Park Memorial Institute; S: schizont; SEG: segmenter.

\section{Competing interests}

The authors declare that they have no competing interests.

\section{Authors' contributions}

SK, TMED and TSP conceived the study, SK performed the laboratory work, SK, TMED and TSP wrote the manuscript. All authors read and approved the final manuscript.

\section{Acknowledgements}

The study was funded in part by the National Health and Medical Research Council (NHMRC) of Australia (grant 458555). TMED is supported by an NHMRC Practitioner Fellowship. The authors acknowledge the facilities, scientific and technical assistance of the Australian Microscopy \& Microanalysis Research Facility at the Centre for Microscopy, Characterisation \& Analysis, The University of Western Australia and the Fremantle Hospital Haematology Unit. 


\section{Author Details}

'School of Physics, M013, The University of Western Australia, 35 Stirling Highway, Crawley WA 6009, Australia and 2School of Medicine and Pharmacology, The University of Western Australia, Fremantle Hospital, Alma Street, Fremantle, WA 6959, Australia

Received: 8 December 2009 Accepted: 3 May 2010

Published: 3 May 2010

\section{References}

1. Florens L, Washburn MP, Raine JD, Anthony RM, Grainger M, Haynes JD, Moch JK, Muster N, Sacci JB, Tabb DL, Witney AA, Wolters D, Wu Y, Gardner MJ, Holder AA, Sinden RE, Yates JR, Carucci DJ: A proteomic view of the Plasmodium falciparum life cycle. Nature 2002, 419:520-526.

2. Lazarus MD, Schneider TG, Taraschi TF: A new model for hemoglobin ingestion and transport by the human malaria parasite Plasmodium falciparum. J Cell Sci 2008, 121:1937-1949.

3. Egan TJ: Haemozoin formation. Mol Biochem Parasitol 2008, 157:127-136.

4. Hempelmann E: Hemozoin biocrystallization in Plasmodium falciparum and the antimalarial activity of crystallization inhibitors. Parasitol Res 2007, 100:671-676.

5. Francis SE, Sullivan DJ Jr, Goldberg DE: Hemoglobin metabolism in the malaria parasite Plasmodium falciparum. Annu Rev Microbiol 1997, 51:97-123.

6. Nalbandian RM, Sammons DW, Manley M, Xie L, Sterling CR, Egen NB, Gingras BA: A molecular-based magnet test for malaria. Am J Clin Pathol 1995, 103:57-64.

7. Paul F, Roath S, Melville D, Warhurst DC, Osisanya JO: Separation of malaria-infected erythrocytes from whole blood: use of a selective high-gradient magnetic separation technique. Lancet 1981, 2:70-71.

8. Ahn SY, Shin MY, Kim YA, Yoo JA, Kwak DH, Jung YJ, Jun G, Ryu SH, Yeom JS, Ahn JY, Chai JY, Park JW: Magnetic separation: a highly effective method for synchronization of cultured erythrocytic Plasmodium falciparum. Parasitol Res 2008, 102:1195-1200.

9. Lavazec C, Sanyal S, Templeton TJ: Hypervariability within the Rifin Stevor and Pfmc-2TM superfamilies in Plasmodium falciparum. Nucleic Acids Res 2006, 34:6696-6707.

10. Duranton C, Huber SM, Tanneur V, Brand VB, Akkaya C, Shumilina EV, Sandu CD, Lang F: Organic osmolyte permeabilities of the malariainduced anion conductances in human erythrocytes. J Gen Physiol 2004, 123:417-426.

11. Hackett S, Hamzah J, Davis TME, St-Pierre TG: Magnetic susceptibility of iron in malaria-infected red blood cells. Biochim Biophys Acta 2009, 1792:93-99.

12. Balu B, Shoue DA, Fraser MJ Jr, Adams JH: High-efficiency transformation of Plasmodium falciparum by the lepidopteran transposable element piggyBac. Proc Natl Acad Sci USA 2005, 102:16391-16396.

13. Staalsoe T, Giha HA, Dodoo D, Theander TG, Hviid L: Detection of antibodies to variant antigens on Plasmodium falciparum-infected erythrocytes by flow cytometry. Cytometry 1999, 35:329-336.

14. Woehlbier U, Epp C, Kauth CW, Lutz R, Long CA, Coulibaly B, Kouyate B, Arevalo-Herrera M, Herrera S, Bujard $\mathrm{H}$ : Analysis of antibodies directed against merozoite surface protein 1 of the human malaria parasite Plasmodium falciparum. Infect Immun 2006, 74:1313-1322.

15. Karl S, David M, Moore L, Grimberg BT, Michon P. Mueller I, Zborowski M, Zimmerman PA: Enhanced detection of gametocytes by magnetic deposition microscopy predicts higher potential for Plasmodium falciparum transmission. Malar J 2008, 7:66

16. Ribaut C, Berry A, Chevalley S, Reybier K, Morlais I, Parzy D, Nepveu F, Benoit-Vical F, Valentin A: Concentration and purification by magnetic separation of the erythrocytic stages of all human Plasmodium species. Malar J 2008, 7:45.

17. Cooke BM, Coppel RL: Cytoadhesion and falciparum malaria: going with the flow. Parasitol Today 1995, 11:282-287.

18. Pouvelle B, Fusai T, Lepolard C, Gysin J: Biological and biochemical characteristics of cytoadhesion of Plasmodium falciparum-infected erythrocytes to chondroitin-4-sulfate. Infect Immun 1998, 66:4950-4956.

19. Karl S, Davis TME, St-Pierre TG: A comparison of the sensitivities of detection of Plasmodium falciparum gametocytes by magnetic fractionation, thick blood film microscopy, and RT-PCR. Malar $J 2009$, $8: 98$
20. Zimmerman PA, Thomson JM, Fujioka H, Collins WE, Zborowski M Diagnosis of malaria by magnetic deposition microscopy. Am J Trop Med Hyg 2006, 74:568-572

21. Taylor LH, Read AF: Why so few transmission stages? Reproductive restraint by malaria parasites. Parasitol Today 1997, 13:135-140

22. Babiker HA, Abdel-Wahab A, Ahmed S, Suleiman S, Ranford-Cartwright L, Carter R, Walliker D: Detection of low level Plasmodium falciparum gametocytes using reverse transcriptase polymerase chain reaction. Mol Biochem Parasitol 1999, 99:143-148.

23. Craig A, Scherf A: Molecules on the surface of the Plasmodium falciparum infected erythrocyte and their role in malaria pathogenesis and immune evasion. Mol Biochem Parasitol 2001, 115:129-143.

24. Wernsdorfer WH, Tasanor O, Wernsdorfer G: In vitro drug sensitivity testing in Plasmodium vivax. Wien Klin Wochenschr 2008, 120:30-33.

25. Grimberg BT, Erickson JJ, Sramkoski RM, Jacobberger JW, Zimmerman PA Monitoring Plasmodium falciparum growth and development by UV flow cytometry using an optimized Hoechst-thiazole orange staining strategy. Cytometry A 2008, 73:546-554.

26. Li Q, Gerena L, Xie L, Zhang J, Kyle D, Milhous W: Development and validation of flow cytometric measurement for parasitemia in cultures of $P$. falciparum vitally stained with YOYO-1. Cytometry A 2007 71:297-307.

27. Karl S, Wong R, St-Pierre TG, Davis TME: A comparative study of flow cytometry-based assessment of in vitro Plasmodium falciparum drug sensitivity. Malar J 2009, 8:294.

28. Deans AM, Rowe JA: Plasmodium falciparum: Rosettes do not protect merozoites from invasion-inhibitory antibodies. Exp Parasitol 2006, 112:269-273.

29. Rowe JA, Claessens A, Corrigan RA, Arman M: Adhesion of Plasmodium falciparum-infected erythrocytes to human cells: molecular mechanisms and therapeutic implications. Expert Rev Mol Med 2009, 11:e16

30. Hamirani YS, Franklin W, Grifka RG, Stainback RF: Methemoglobinemia in a young man. Tex Heart Inst $J$ 2008, 35:76-77

31. Pamplona A, Hanscheid T, Epiphanio S, Mota MM, Vigario AM: Cerebral malaria and the hemolysis/methemoglobin/heme hypothesis: shedding new light on an old disease. Int J Biochem Cell Biol 2009, 41:711-716.

32. Uko EK, Udoh AE, Etukudoh MH: Methaemoglobin profile in malaria infected children in Calabar. Niger J Med 2003, 12:94-97.

33. Reilly HB, Wang H, Steuter JA, Marx AM, Ferdig MT: Quantitative dissection of clone-specific growth rates in cultured malaria parasites. Int J Parasitol 2007, 37:1599-1607.

doi: 10.1186/1475-2875-9-116

Cite this article as: Karl et al., Parameterization of high magnetic field gradient fractionation columns for applications with Plasmodium falciparum infected human erythrocytes Malaria Journal 2010, 9:116

\section{Submit your next manuscript to BioMed Central and take full advantage of:}

- Convenient online submission

- Thorough peer review

- No space constraints or color figure charges

- Immediate publication on acceptance

- Inclusion in PubMed, CAS, Scopus and Google Scholar

- Research which is freely available for redistribution 